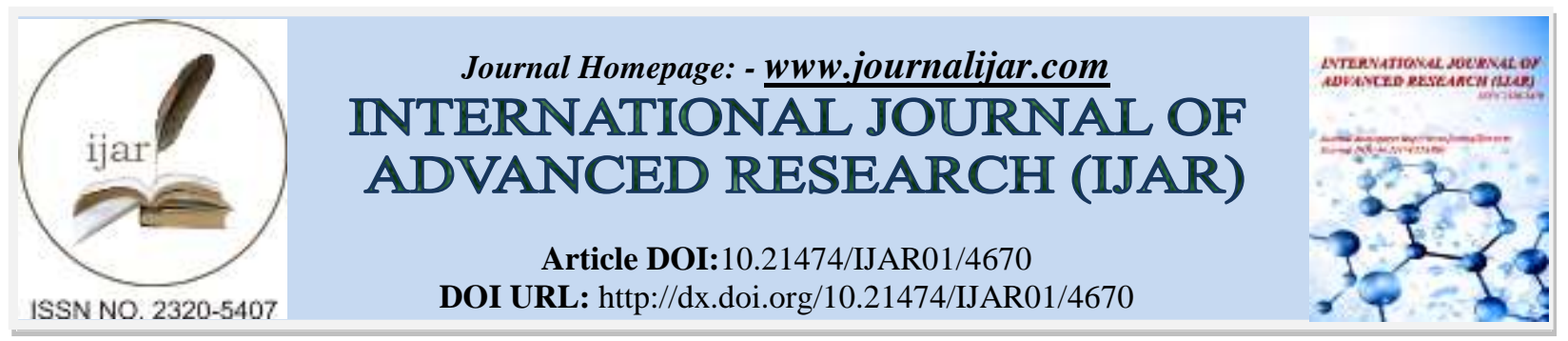

RESEARCH ARTICLE

\title{
TORSION OF ACCESSORY SPLEEN- A RARE CAUSE OF ACUTE ABDOMEN IN PREGNANCY: A CASE REPORT.
}

Dr Samir, Dr Bhushan, Dr Tarun and Dr Dnyaneshwar.

\section{Manuscript Info}

Manuscript History

Received: 26 April 2017

Final Accepted: 30 May 2017

Published: June 2017

\section{Abstract}

Accessory spleen is the most common congenital anomaly of splenic development but torsion of accessory spleen is a rare entity with varied presentation depending upon its location. We report a rare case of torsion of accessory spleen in a 26year old 14 weeks pregnant female .She underwent exploratory laparotomy and the accessory splenic mass was removed. Postoperative course was uneventful. Torsion of accessory spleen though rare should be consider as differential diagnosis for acute or subacute abdominal pain in pregnancy.

Copy Right, IJAR, 2017,. All rights reserved.

\section{Introduction:-}

Accessory spleen or splenunculi is the most common anomaly of splenic embryology that consists of single or multiple ectopic splenic tissues separated from the main body of the spleen with its own blood supply.The prevalence of accessory spleen is $10-30 \%$ in autopsies series, and 3-11\% of computed tomography (CT) and ultrasound (US) examinations ${ }^{[1-4]}$.

Although accessory spleen are usually asymptomatic, they may present with symptoms, as in our case, related to acute torsion/infarction. Apart from abdominal pain there are no specific clinical or laboratory parameters pointing towards the diagnosis making it a diagnostic dilemma preoperatively. However ultrasonographic doppler and MRI abdomen with angiography are the most useful diagnostic methods in pregnant females.

\section{Case Report:-}

A 26-year-old pregnant female in $14^{\text {th }}$ week of pregnancy presented with 4-day history of left-lumbar region pain that slowly aggravated and become continuous. Physical examination revealed left-side abdominal tenderness, most markedly in the left lower quadrant. The bowel sounds were decreased and a vague firm mass was palpated in the left lumbar region. Her vitals were pulse rate $82 / \mathrm{min}, \mathrm{BP} 120 / 80 \mathrm{mmHg}$, respiration rate $20 / \mathrm{min}$ and body temperature $37.7 \mathrm{o} \mathrm{C}$. She had previously been in good health and her past medical history was unremarkable except for two previous lower segment caesarean sections, last being 2 yrs back. The laboratory findings showed a WBC count of $11,800 / \mathrm{mm}^{3}$, hemoglobin $9.7 \mathrm{~g} / \mathrm{dl}$, platelets $342,000 / \mathrm{mm}^{3}$, PT $13.1 \mathrm{sec}$ (INR 0.97), serum $\mathrm{Na}^{+} 134 \mathrm{mEq} / \mathrm{L}$, and serum $\mathrm{K}^{+} 4.0 \mathrm{mEq} / \mathrm{L}$.

USG Abdomen showed a hypoechoic lesion in the left lumbar region overlying the lower pole of kidney. MRI abdomen showed a left lumbar region mass with a twisted vascular pedicle arising from splenic vessels.[Figure 1] Doppler ultrasound showed no vascular flow within the hypoechoic mass in the left upper abdomen . 


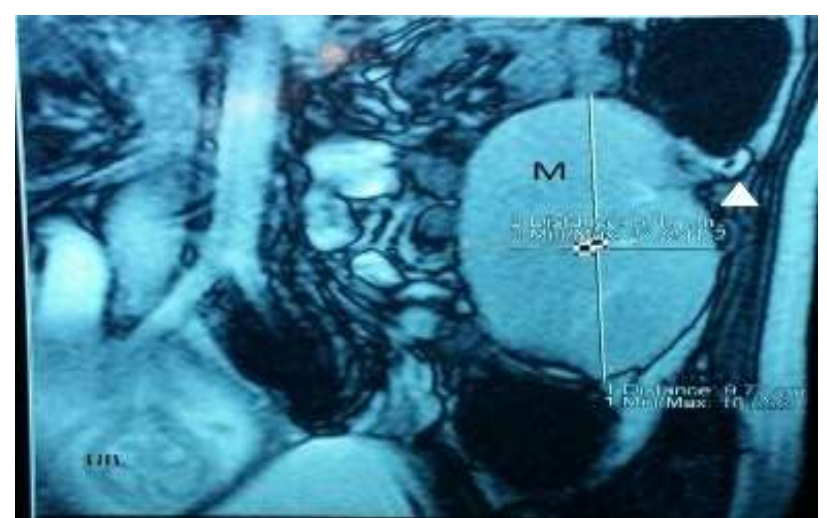

Figure 1:- Coronal section of MRI abdomen showing mass(M) in the left lumbar region with arrowhead showing the twisted vascular pedicle laterally.

Exploratory laparotomy was done with the suspected diagnosis of torsion of an accessory spleen. Exploration showed a large, rounded violet mass with a twisted vascular pedicle, located in left lumbar region with small bowel and mesentry adhered to it.[Figure 2] Accessory splenic mass was

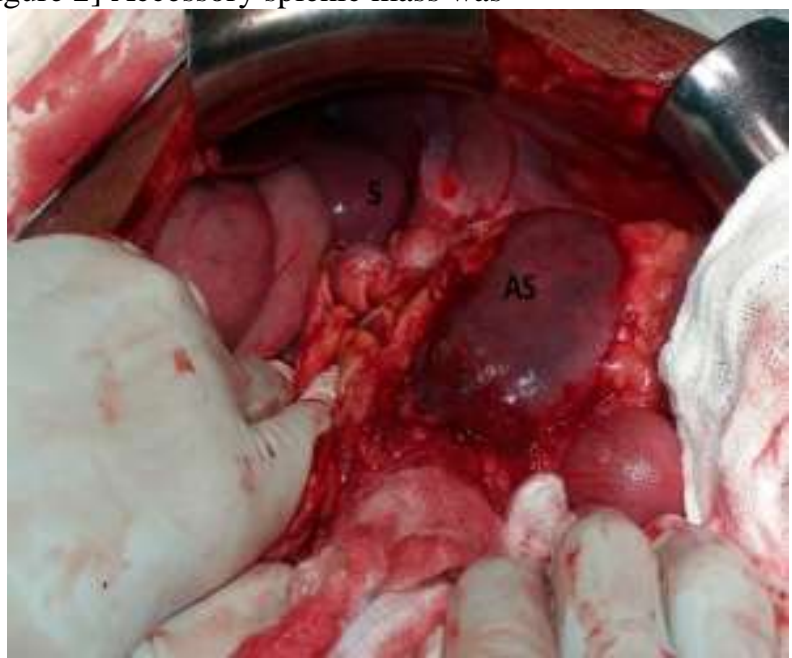

Figure 2:- Intraoperative photo showing accessory spleen (AS) in the lumbar region and native spleen (S)in the left hypochondriac region.

Excised after ligating the vascular pedicle. The postoperative period was uneventful, USG suggestive of live intra uterine foetus and the patient was discharged on the $5^{\text {th }}$ postoperative day.

\section{Discussion:-}

An accessory spleen most likely originates from incomplete fusion of the mesenchymal buds in dorsal mesogastrium. It is the most common congenital anomaly of splenic development. Over $80 \%$ of accessory spleens are found in the region of the splenic hilum and vascular pedicle ${ }^{[6]}$.

Usually, accessory spleen is asymptomatic, rare complications being torsion and infarction, rupture with bleeding, and infection with abscess.

Torsion of accessory spleen with resultant infarction and necrosis may cause an acute abdomen secondary to long vascular pedicle twisting.

It occursat any age, but more than half of the reported cases occurredin children. Torsion of accessory spleen in pregnancy is extremely rare that only one case has been reported in the literature so far ${ }^{[5]}$.In pregnancy torsion of spleen has varied presentation depending upon its location. Its occurrence has been attributed to abdominal wall laxity during pregnancy, multiparity, lack of intraabdominal space during pregnancy. 
Acute abdomen with nonenhancing mass on imaging studies should raise strong clinical suspicion regarding torsion of accessory spleen. Ultrasonography with Doppler study will be the initial investigation of choice. CECT is investigation of choice except in pregnancy where MRI is used.As the condition is very rare diagnosis requires a very high index of suspicion in order to investigate accordingly to reach the diagnosis. So it should be consider as differential diagnosis for acute or subacute abdominal pain in pregnancy.

\section{References:-}

1. Dachman Ah. Anomalies of congenital disorders of the spleen. In:Gore RM, Levine MS, Laufer I, editors. Textbook of gastrointestinalradiology. Philadelphia: WB Saunders; 1994. p. 2238-50.

2. Federle MP. The spleen. In: Moss AA, Gamsu G, Genant HK, editors.Computed tomography of the body with magnetic resonance imaging.2nd ed. Philadelphia, PA: Saunders; 1992. p. 1059-90.

3. Babcock TL, Coker DD, Haynes JL, et al. Infarction of an accessoryspleen causing an acute abdomen. Am J Surg 1974;127(3):336-7.

4. Ali Tavakkoli,(2013) The Spleen.Maingot Abdominal operation p.1239-1240.

5. Catani M, De Milito R, Rattà G, Abati G, Chiaretti M, Rengo M. Laparoscopy in an abdominal emergency: the diagnosis and therapy in 3 clinical cases of acute abdomen. Ann Ital Chir. 1999 Mar-Apr;70(2):265-8; discussion 268-9.

6. Adrain E. Park, EduardoM. Targarona, Igor Belyansky (2015) Spleen, Schwartz Principles of surgery p. 14241425. 